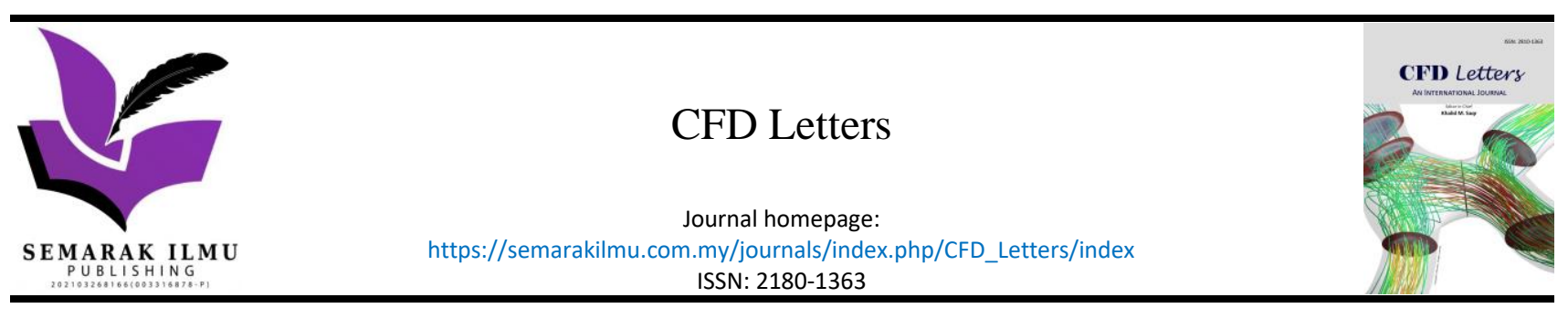

\title{
Thermal Comfort Analysis for Overhead and Underfloor Air Distribution Systems
}

\author{
Firas Basim Ismail ${ }^{1,}{ }^{*}$, Nizar F.O. Al-Muhsen ${ }^{2}$, Ain Amira Johari ${ }^{1}$ \\ Power Generation Unit, Institute of Power Engineering (IPE), Universiti Tenaga Nasional (UNITEN), 43000 Kajang, Selangor, Malaysia \\ Technical Instructor Training Institute, Middle Technical University, Baghdad, Iraq
}

\section{ARTICLE INFO}

\section{Article history:}

Received 23 August 2021

Received in revised form 9 November 2021

Accepted 11 November 2021

Available online 15 December 2021

\section{Keywords:}

Thermal comfort analysis; Overhead AC system; Underfloor AC system; CFD Modelling

\section{ABSTRACT}

Underfloor and overhead air distributions are two types of Heating Ventilating and Air Conditioning (HVAC) system in which both differs in term of channelling the supplied air into a space. Underfloor air distribution (UFAD) system channels the supplied air from the underfloor plenum and goes to the return vent at the ceiling. On the other hand, the overhead air distribution (OHAD) system utilizes the ceiling-to-ceiling air pathway approach. In this study, A developed HVAC model was proposed. Ansys Fluent program was used to numerically investigate the best thermal comfort of the proposed model in terms of occupant satisfaction by referring to ASHRAE Standard. Two scenarios were designed and adopted in the computational investigation which is OHAD and UFAD. Three heat-generating parameters were involved which are a room lamp, personal computer and occupant. The attained computational fluid dynamic (CFD) simulation results were validated. Generally, the attained CFD results showed that the UFAD system could perform better compare to the OHAD system even though the OHAD system could have some benefits. Specifically, the UFAD system provided the best thermal performance whereas the OHAD system was found to be less efficient in providing thermal comfort to the occupant and consumed a greater amount of energy because it was required to cool down the whole room instead of being cooled partly. The CFD results confirmed that the UFAD system was capable of maintaining the room temperature at $26^{\circ} \mathrm{C}$ at a height below $2.0 \mathrm{~m}$ compared to $1.2 \mathrm{~m}$ of the OHAD system. In conclusion, the UFAD system could provide better indoor air quality, and it could have superior performance for the tropic weather regions such as Malaysia compared to that of the OHAD system. Besides, using the UFAD system could be represented a preventive action that could be proposed to solve the mould growth inside any occupied room.

\section{Introduction}

Providing a comfortable and healthy atmosphere for the indoor working staff requires a merit interior design. The occupation rules of the inside workplaces worldwide have been dramatically affected by COVID-19. During and the era after the COVID-19 pandemic, the air-conditioning and ventilation quality for any staff-occupied room has become one of the imperative conditions to

\footnotetext{
* Corresponding author.

E-mail address: firas@uniten.edu.my (Firas Basim Ismail)
} 
resume office work. The greenhouse gas emission that could worsen global warming and climate change is another reason that encourages the researcher to optimize the performance of the airconditioning and ventilation systems. In fact, the relation between energy consumption and buildings is strong in such a way that it becomes the major contributor to global warming [1]. The energy consumption of a building represents $40 \%$ of the total energy used by the world [2,3]. The, heating, Ventilating and Air Conditioning (HVAC) system consume a high amount of energy in such a way that it is entitled as the largest primary energy end-use in commercial buildings [4]. The issue has triggered the researchers to investigate and develop a solution that could reduce the global warming effect by designing an HVAC system that could operate in an energy-sustainable mode [5].

The main purpose of HVAC systems in buildings is to provide thermal comfort to the occupants by enhancing indoor air quality (IAQ) and thermal comfort. Thermal comfort is a condition that the people express satisfaction with the thermal environment, and is analyzed by subjective evaluation [6]. It was reported that the effecting parameters on the level of thermal comfort are metabolic rate, clothing insulation, air temperature, radiant temperature, airspeed and humidity [7]. The term thermal comfort is subjective as a result of different metabolic rates, clothing insulation and dynamic adaptation of humans towards the surroundings. This is due to the adaptive approach where when there is a change in the condition that produces discomfort, people would react in such a way that it would restore their comfort. The adaptive approach such as changing clothing, posture, activity and air movement could contribute to restoring thermal comfort. The amount of adaptive opportunity that exists in the building would cause no direct effect on the comfort condition, but it would enable the occupants to alter the condition to suit themselves. The range of comfortable conditions relies on the adaptive opportunities own by the individual and characteristics of the building [8].

The term thermal comfort refers to the state at which the heat balance across the body and environment reaches an equilibrium state [9]. The thermal comfort condition can be evaluated by using two models namely the Predicted Mean Vote (PMV) and adaptive model. However, the PMV model may not give an accurate result since it depends on the climate zone. Therefore, the adaptive model was recommended to be used as an alternative method of calculating the thermal comfort in a naturally ventilated buildings to validate the PMV model [7]. The calculation in the PMV model involves measurable quantities including air velocity, air temperature, mean radiant temperature and relative humidity, which at the same time considers the clothing insulation factors and metabolism rate of an individual. The PMV model results from a vote generated based on the index that allows the occupants to express their thermal sensation towards the conditioned space. The result showed that the PMV model in AC building presented a specific trend of overprediction without regard to the type of season and weather.

Underfloor air distribution system was founded in the 1950s, and first launched in the office buildings in West Germany in 1970s. The UFAD system was invented to eliminate the enormous amount of heat loads in the spaces. The UFAD supplies the conditioned air through the supply vents located at the floor level which utilizes underfloor supply plenum and elevated access floor. This system could help the occupants in reducing the building life cost, energy usage, and also improving ventilation efficiency and indoor air quality.

Alajmi et al., [10] reported that the principle of UFAD system is to supply conditioned air to the occupied zone within only $1.8 \mathrm{~m}$ height, which is the average height of a human. Therefore, the load of the sensible zone can be reduced if the upper volume of the occupied zone is subtracted from the load of the air conditioning system. In another word, the air volume of any occupied room can be stratified into four thermal zones, namely, the bottom cooler zone, lower narrow zone, transitional zone, and upper warmer zone. Moreover, the authors found that the height of the occupied room could also affect the air stratifications. 
In contrast, Tsai et al., [11] found that the change in the supplied air temperature had a slight influence on the vertical temperature profile. Practically, the temperature stratification in the UFADutilizing-enclosed space was particularly influenced by the thermal length scale of the floor supply ducts. The authors observed that the temperature stratification was weak when the thermal length scale of the floor supply ducts exceeds 1.0. On the other side, the lower layer temperature could be raised by increasing the vertical momentum. When the supply airflow increased, the temperature stratification decreased caused by greater supply momentum. The maximum height of the supplied conditioned air that can be reached was denoted by throw height (T.H.) and have a range of $0.9 \mathrm{~m}$ to $1.9 \mathrm{~m}$ based on the experimental results. Besides. the height of maximum gradient temperature, stratification height (S.H.) is directly proportional to the rate of the supplied airflow.

Sipes et al., [12] defined Overhead Air Distribution (OHAD) as an HVAC system that infuses conditioned air that consists of a mixture of fresh and recirculated air into a building space in such a way that it indirectly enters the occupied zone. The term 'occupied zone' was explained as the region at which it is a foot away from the walls and six feet above the floor level inside the building space. Best design of OHAD system is when it capable of delivering the supply air in uniform mixing state into the building space. In order to measure the effectiveness of supply air distribution system in controlling the air quality in the occupied zone, ASHRAE Standard 62.1 introduced a term called Zone Air Distribution Effectiveness (Ez). For cooling, the Ez for overhead system is 1.0 while for heating, the $E z$ is 0.8 .

Many original related research works were reviewed and their main outcomes were highlighted. However, few studies numerically investigated at the same time the two types of underfloor and overhead air distributions HVAC systems. In this study, a developed HVAC model was proposed. Ansys Fluent program was used to computationally investigate the optimal thermal comfort of the proposed HVAC model regarding occupants' satisfaction by referring to ASHRAE Standard. Two HAVC systems of OHAD and UFAD were designed and used in the numerical investigation of this study. The in-room heat loads plus the occupant were taken into consideration in the presented study.

\section{Methodology}

This subsection is dedicated to discussing the detailed method on how to investigate the thermal comfort level for both UFAD and OHAD models by using Computational Fluid Dynamic (CFD) simulation. Five testing conditions were simulated in this work, and the attained results were discussed and analyzed in the next subsection. The proposed design, adopted boundary conditions, the used turbulence flow model, mesh independence testing and a detailed setup for the simulations are also presented. To make the proposed CFD simulation more reliable, the used boundary and initial conditions for this study are highly similar to those mentioned in reference $[11,13]$. However, not all the important boundary conditions were stated so proper values of boundary conditions are assigned for this study. Accordingly, small error percentages between the compared article and this study result were noticed. Step by step methodology is described including the used mathematical models and mesh quality. In this study, two types of HVAC comprising UFAD and OHAD systems were investigated by using CFD simulation. Due to the high cost of such experiments, the CFD simulation has become one of the most convenient methods to study the air motion in a space connected with an air distribution design system. The outcome from the CFD simulations could show the thermal distribution, airflow distribution and relative humidity. The attained results will be discussed and analyzed in order to determine whether the proposed HVAC system could provide thermal comfort to the occupant or not. 


\subsection{Initial and Boundary Conditions}

There are few assumptions were made before conducting the CFD simulations. Firstly, the outside design conditions were selected from a long-term statistical database. It does not necessarily represent any particular year but are representing the location of the building. As Malaysia has the tropical weather, it was assumed to be in the region of summer for the purpose of measuring the thermal comfort. Secondly, the occupancy of the building was assumed to be at full design capacity and operating office activity for the whole period of working hours. Thirdly, all building equipment and appliances were assumed to be operating at a reasonable rate of capacity. As aforementioned, thermal comfort was associated with IAQ which also correlated with the level of contaminant in a space. ASHRAE [7] however did not mention contaminant level as a factor that provide thermal comfort. Two parameters would be evaluated from the six parameters that provide thermal comfort as mentioned by ASHRAE which are air temperature, air speed and humidity. A total of five simulations were conducted in this research study which are 2D models for UFAD and OHAD systems, 2D models with two occupants for UFAD and OHAD system, 2D model for UFAD system at different diffuser position and lastly 3D model for UFAD system with three diffusers. The boundary conditions for both UFAD and OHAD models are listed in the Tables 1 and 2.

Table 1

Initial and boundary conditions for OHAD model

\begin{tabular}{lll}
\hline \multicolumn{2}{l}{ Overhead Air Distribution (OHAD) } & system \\
\hline Named selections & Variables & Value and units \\
\hline Air_cond_in & Inlet velocity & $0.6 \mathrm{~m} / \mathrm{s}$ \\
& Inlet temperature & $291 \mathrm{~K}$ \\
Occupant_heat_source & Heat flux & $58.5 \mathrm{~W} / \mathrm{m}^{2}$ \\
Computer_heat_source & Heat generation & $1227.68 \mathrm{~W} / \mathrm{m}^{3}$ \\
Lighting_heat_source & Heat generation & $29326 \mathrm{~W} / \mathrm{m}^{3}$ \\
\hline
\end{tabular}

Table 2

Initial and boundary conditions for UFAD model

\begin{tabular}{lll}
\hline \multicolumn{2}{l}{ Underfloor Air Distribution (UFAD) system } \\
\hline Named selections & Variables & Value and units \\
\hline Air_cond_in & Inlet velocity & $1.0 \mathrm{~m} / \mathrm{s}$ \\
& Inlet temperature & $293 \mathrm{~K}$ \\
Occupant_heat_source & Heat flux & $58.5 \mathrm{~W} / \mathrm{m}^{2}$ \\
Computer_heat_source & Heat generation & $1227.68 \mathrm{~W} / \mathrm{m}^{3}$ \\
Lighting_heat_source & Heat generation & $29326 \mathrm{~W} / \mathrm{m}^{3}$ \\
\hline
\end{tabular}

\subsection{Internal Load Estimation}

People generates both sensible and latent heat. The rate of sensible and latent heat generated by each human being varies and it depends on the capacity of the occupancy and their activity level, as shown in Table 3. Part of the heat transferred by the occupants is by radiation. Therefore, the Cooling Load Factor (CLF) could be utilized. However, the factor considers the time lag between the peak temperature of the exterior and the interior of the building. Practically, the transferred heat from the outside of building varies with respect to time. For instance, the temperature in the morning is colder compare to the temperature in the afternoon. External cooling load behaves dynamically corresponding to the weather. The sensible and latent heat transfer by occupants to the conditioned space are represented in Eqs. (1) and (2) respectively. In addition, lighting system produces latent 
heat to the surroundings. Light plays an important role in the building design as it is the basic requirement of a building and it also contributes to the cooling load. If the light is set to be turned on 24 hours daily, the power input of the light would be equivalent to the cooling load. However, designers mostly apply energy-saving practices in everyday life aiming to reduce electricity bills related to the lighting and cooling systems. When light is turned off, the cooling load would be reduced, but not necessarily equals to zero. Heat due to lighting and equipment need to be considered as they are important parameters that could contribute to the internal heat gain. Eqs. (3) and (4) show the generated sensible heat caused by lighting another office equipment.

\section{Table 3}

Rates of heat gain from occupants of conditioned space $[13,14]$

\begin{tabular}{|c|c|c|c|c|c|c|c|c|c|}
\hline \multirow[t]{2}{*}{ Degree of Activity } & \multirow[t]{2}{*}{ Typical Application } & \multicolumn{2}{|c|}{$\begin{array}{l}\text { Total Heat } \\
\text { Adults, Male }\end{array}$} & \multicolumn{2}{|c|}{$\begin{array}{l}\text { Total Heat } \\
\text { Adjusted }\end{array}$} & \multicolumn{2}{|c|}{ Sensible Heat } & \multicolumn{2}{|c|}{ Latent Heat } \\
\hline & & Btu/hr & W & $\mathrm{Btu} / \mathrm{hr}$ & W & Btu/hr & W & Btu/hr & W \\
\hline Seated at theater & Theater-matinee & 390 & 114 & 330 & 97 & 225 & 66 & 105 & 31 \\
\hline Seated at theater & Theater-evening & 390 & 114 & 350 & 103 & 245 & 72 & 105 & 31 \\
\hline Seated, very light work & Offices, hotels, apartments & 450 & 132 & 400 & 117 & 245 & 72 & 155 & 45 \\
\hline $\begin{array}{l}\text { Moderately active } \\
\text { office work }\end{array}$ & Offices, hotels, apartments & 475 & 139 & 450 & 132 & 250 & 73 & 200 & 59 \\
\hline $\begin{array}{l}\text { Standing, light work; } \\
\text { walking }\end{array}$ & $\begin{array}{l}\text { Department store, retail } \\
\text { store }\end{array}$ & 550 & 162 & 450 & 132 & 250 & 73 & 200 & 59 \\
\hline Standing; walking & Drugstore, bank & 550 & 162 & 500 & 146 & 250 & 73 & 250 & 73 \\
\hline Sedentary work & Restaurant & 490 & 144 & 550 & 162 & 275 & 81 & 275 & 81 \\
\hline Light bench work & Factory & 800 & 235 & 750 & 220 & 275 & 81 & 475 & 139 \\
\hline Moderate dancing & Dance hall & 900 & 264 & 850 & 249 & 305 & 89 & 545 & 160 \\
\hline $\begin{array}{l}\text { Walking } 3 \mathrm{mph} \text {; light } \\
\text { machine work }\end{array}$ & Factory & 1000 & 293 & 1000 & 293 & 375 & 110 & 625 & 183 \\
\hline Bowling & Bowling alley & 1500 & 440 & 1450 & 425 & 580 & 170 & 870 & 255 \\
\hline Heavy work & Factory & 1500 & 440 & 1450 & 425 & 580 & 170 & 870 & 255 \\
\hline $\begin{array}{l}\text { Heavy machine work; } \\
\text { lifting }\end{array}$ & Factory & 1600 & 469 & 1600 & 469 & 635 & 186 & 965 & 283 \\
\hline Athletics & Gymnasium & 2000 & 586 & 1800 & 528 & 710 & 208 & 1090 & 320 \\
\hline
\end{tabular}

$$
\begin{aligned}
& Q s, \text { occupants }=(\text { No. of occupant })(\text { Sensible heat gain per person }) \cdot C L F \\
& Q l, \text { occupants }=(\text { No. of occupant })(\text { Latent heat gain per person })
\end{aligned}
$$

$$
Q s, \text { light }=3.41 W F u F s
$$$$
Q e=C\left(\frac{P}{E m}\right) F l F u
$$

\subsection{Computational Fluid Dynamics (CFD) Model and Simulation}

Computational Fluid Dynamics (CFD) simulation could offer a reasonable method that could give a good understanding to the thermophysical characteristics for the conditioned-air inside any closed space [15]. It could help in visualizing the in-room fluid flow, and heat transfer between fluids in wide range applications in order to achieve preliminary results and understanding for the designated models [16-18]. In order to attain as possible accurate results, the initial and boundary conditions 
need to be set accurately. Therefore, in this study, it is essential to select appropriate initial and boundary conditions for the numerical analysis for the proposed Underfloor Air Distribution (UFAD) and Overhead Air Distribution (OHAD) system. The CFD simulation for both systems would be varied because of different boundary conditions due to the different positions of the supply air-conditioned vents. In order to make the calculation more realistic, few assumptions were made since occupants may have different body temperatures and patterns of motion. This included the inlet air temperature and velocity. The generated heat by the occupants, electrical devices, and lighting equipment were also considered.

The proposed two-dimensional geometry was designed for a working office that needs to be considered first. The design and dimensions of the office was selected to be similar previously validated design in reference [13]. The major dimensions of the proposed design were set to be $(2.0$ $\mathrm{m}$ width $\times 2.7 \mathrm{~m}$ height). The model was structured to be contained one occupant and an office desk, as shown in Figure 1. The subjects that could be considered as a heat generator inside the office such as the occupant person and electrical appliances including the lamp and computer were also considered in the proposed design. A constant value of heat generation was assigned to the heat generators objects during the calculation. This model was designed to be applicable for both the OHAD and UFAD systems for the purpose of comparison. For the OHAD system, the supply air would be channeled from the ceiling and return to the other side of the ceiling while for the UFAD system, the supply air would be channeled from the floor to the ceiling. The return vents for both systems would be the same.

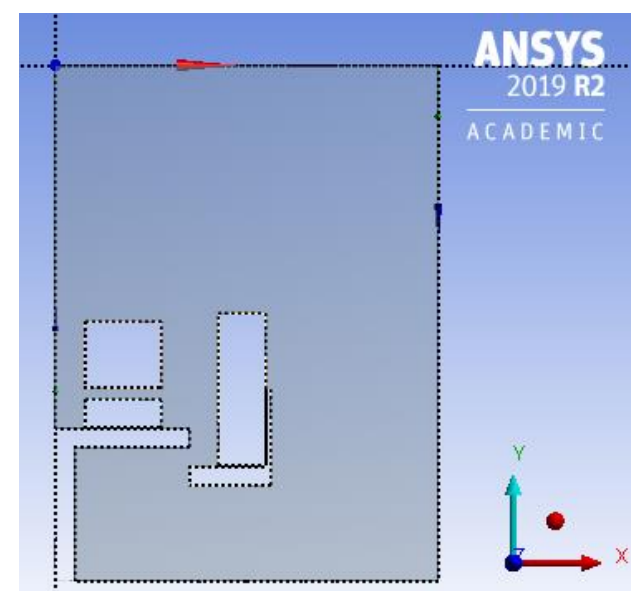

Fig. 1. Design parameter for both UFAD and OHAD models

Quadrilateral mesh type was used for the meshing process for the proposed geometry. This is because the office design consists of simple shapes. Therefore, it was believed that the quadrilateral mesh type was a reasonable choice to be used for this CFD model. It worth to mention that the idea behind the mesh generation is to discretize the governing equations and solve them inside each of the subdomains or element [19]. Element size refers to the size of the subdomains. The smaller the size of the element, the higher the number of subdomains created to fulfil the size of the domain [20]. Since the smaller subdomains leads to high number of elements, the memory of the computer needs to be large enough to occupy the number of elements. For this study, the element size was initially set to be $0.001 \mathrm{~m}$ but the software failed to generate the mesh. Therefore, as shown in Figure 2 , the element size of $0.01 \mathrm{~m}$ was set to generate the required mesh in order to run the calculation of this study. Besides, the element size could also affect the needed time to generate the required mesh. In another word, if the computer has large memory, the time taken to finish the mesh 
generation would be shorter. The time taken to finish the mesh generation using element size of 0.1 $\mathrm{m}$ is shorter compare to required time taken to finish the mesh generation by using element size of $0.01 \mathrm{~m}$.

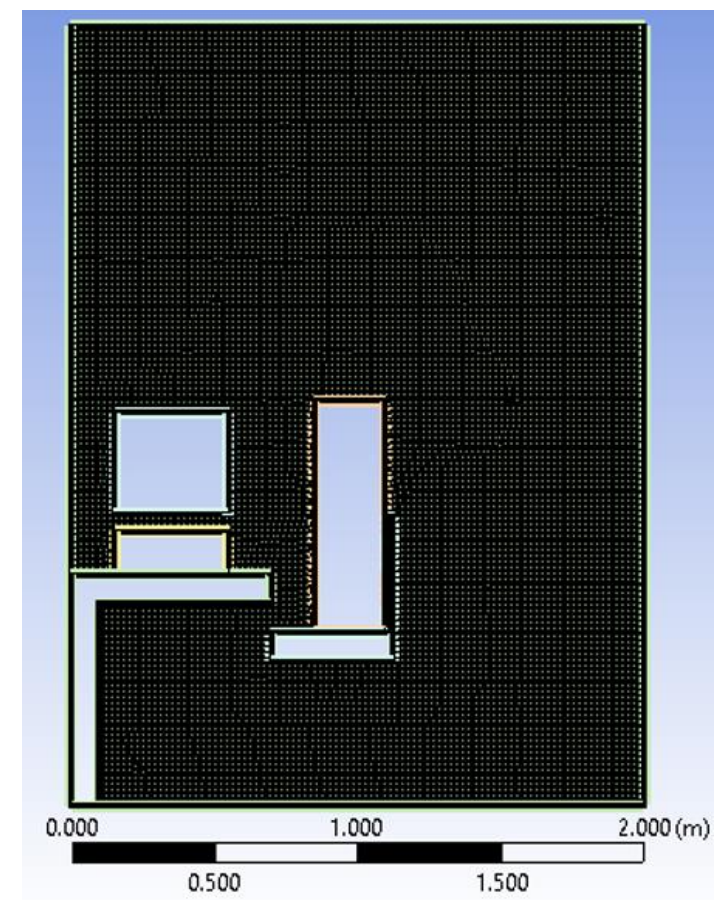

Fig. 2. Meshed geometry with $0.01 \mathrm{~m}$ element size

A mesh independence test was conducted in this study at different element sizes of the generated mesh by running the simulation at different element sizes and compare the attained results accordingly. The main purpose of the independence test is to determine the optimum element size that should be used for the simulation. Minimizing the size of the element simply means rising the number of elements in the designed model. However, the immense amount of elements would require a higher computational cost. A smaller size of element would result in high accuracy solution. However, the time taken to finish the solution would be prolonged. Four element sizes simulations were compared in this study and the temperature profile was selected as a parameter to observe which element size is likely to be the optimum element size for this simulation. Table 4 demonstrates the data for the mesh independence test corresponding to the interior temperature of the room. The data obtained were measured from the inlet vent and directed upward to the ceiling of the room. Based on the data obtained, each element size shows the same trend of temperature. The temperature of the room increases slightly as it goes away from the inlet vent. 
Table 4

Temperature of the interior room at different size of elements

\begin{tabular}{lllll}
\hline Element size $(\mathbf{m})$ & $\mathbf{0 . 0 1 2}$ & $\mathbf{0 . 0 1}$ & $\mathbf{0 . 0 0 8}$ & $\mathbf{0 . 0 0 6}$ \\
\hline Height $(\mathbf{m})$ & \multicolumn{4}{l}{ Temperature $\left({ }^{\circ} \mathbf{C}\right)$} \\
0.00 & 20.00 & 20.00 & 20.00 & 20.00 \\
0.30 & 20.00 & 20.00 & 20.00 & 20.00 \\
0.60 & 20.03 & 20.04 & 20.03 & 20.00 \\
0.90 & 20.04 & 20.10 & 20.07 & 20.00 \\
1.20 & 20.04 & 20.10 & 20.08 & 20.00 \\
1.50 & 20.04 & 20.09 & 20.07 & 20.00 \\
1.80 & 21.70 & 20.08 & 20.06 & 20.06 \\
2.10 & 22.40 & 20.70 & 20.46 & 20.07 \\
2.40 & 22.30 & 22.47 & 21.87 & 20.20 \\
2.70 & 21.74 & 22.19 & 22.32 & 22.36 \\
\hline
\end{tabular}

Figure 3 shows the temperature against height with a variation of the element size. Different element size has a different point of temperature rising. Element size of 0.006 has a significant temperature rise at $2.5 \mathrm{~m}$ while the largest element size, 0.012 has a temperature rise at $1.5 \mathrm{~m}$. The final temperature for element size of $0.01 \mathrm{~m}, 0.008 \mathrm{~m}$, and $0.006 \mathrm{~m}$ do not differ that much and it can be said roughly all end at $22^{\circ} \mathrm{C}$. Therefore, the element size of $0.01 \mathrm{~m}$ is considered the optimum size to be applied for this simulation because of the constant value of the final temperature.

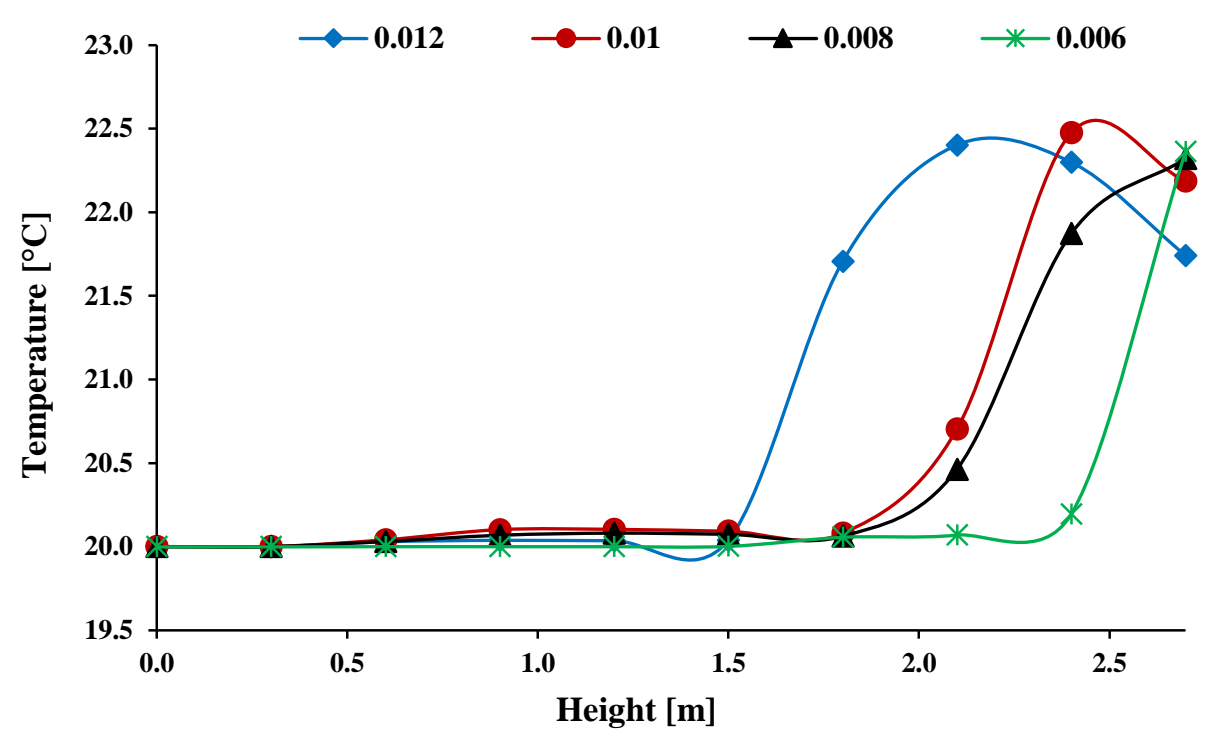

Fig. 3. Temperature against height at various element size

\section{Results and Discussions}

In this section, all the results were obtained based on the simulation conducted for UFAD and OHAD systems. The thermal comfort analysis was discussed according to the data obtained for the air velocity, temperature, and relative humidity, which were commonly discussed in many research papers [21]. The attained results from this work were validated with the simulation results of the published paper [13]. In addition, additional simulations were conducted to observe and investigate the performance of both models in providing thermal comfort when the number of occupants and position of the diffuser were varied. 


\subsection{Air Velocity Distribution}

Figure 4 shows the velocity contour for the UFAD model for both results obtained from the simulation of this study and reference [13]. It can be observed that the direction of airflow in the room. The maximum recorded airflow velocity is $0.6 \mathrm{~m} / \mathrm{s}$ which is concentrated at the inlet vent. The flow goes straight upwards for both models and slanted to the right towards the outlet vent. At the back of the occupant, both models show a recirculation occurred. Recirculation is also detected at the bottom region under the seat of the occupant. From the particle simulation, there is a slight recirculation spotted at the head level of the occupant. This recirculation occurred due to the cold airflow passed through the heat generated from the occupant and the computer which make the warmer air approach the upper region because of their lighter density. The presented CFD simulation shows no recirculation noticed at the head level of the occupant. This difference might be due to the excessively high value of heat generation applied for the computer which led the recirculation to occur at the top of the computer instead of in front of the occupant. The inlet velocity is higher than the inlet velocity used for the OHAD system. Hence, temperature stratification could be reduced as a result of the higher momentum of the supplied air [13]. Low-temperature stratification can result in energy-saving because the air conditioning system only cools down the space at a certain level whereas the height of a human is only up to $1.8 \mathrm{~m}$. The other $0.9 \mathrm{~m}$ would be occupied with the warmer regions due to the thermal stratification effect and low density of warm air. Other than that, the floor-to-ceiling airflow creates a better indoor air quality because it maintains the cool and fresh air to the conditioned air [22]. This statement is also supported by reference [7, 21]. Ali et al., [10] also mentioned that floor-to-ceiling flow enhances ventilation efficiency and IAQ. As supported by Ho et al., [13], better IAQ manages to promote a better occupant respiration experience for the reason that this flow direction effectively clears away the contaminant in the conditioned space. Moreover, Songkran et al., [23] mentioned that the inlet velocity is able to transfer the interior room warm air that contains a high level of contaminant out of the room while supplying fresh air into the room. However, the UFAD system demonstrates a poorer distribution to the airflow inside the occupied room. On the other hand, less mixing zone in the room contributes to the thermal stratification $[10,13]$.

On the other side, the velocity used for the UFAD model which is $0.6 \mathrm{~m} / \mathrm{s}$ does not comply with the Standard 55-2017 [7], which is set the requirement for a conditioned room having 0.012 (kg. $\mathrm{H} 2 \mathrm{O} / \mathrm{kg}$ ) dry air humidity ratio that should have an inlet velocity of less than $0.2 \mathrm{~m} / \mathrm{s}$. In spite of the fact that Songkran et al., [23] indicated that the high inlet velocity could boost up the fresh air suction rate into the room while extracting more warm air into the external environment, this may induce cold feet effect to the occupant. Sures et al., [22] pointed out that the maximum velocity of air supply for the UFAD system should be less than $2 \mathrm{~m} / \mathrm{s}$. Figure 5 shows the velocity contours for the OHAD system from the CFD simulation of this study and from reference [13]. It can be observed that a portion of the airflow switches direction once it is in contact with the computer. From the reported CFD simulation results of reference $[13,23]$, a whirlpool was detected at the corner behind the occupant due to the intersection of thermal and pressure of the wind [23]. The downward flow of air is imposed by the forced momentum at the inlet and gravitational effect. The main reason why most of the main flow tends to move down is because the low temperature of the supply air makes the air become high dense. Recirculation is observed at the top of the occupant for both studies, this study and reference [13]. This phenomenon occurred due to the mixed convection generated by the main supply of air itself and the natural convection imposed by the heat-generating objects [13, 24]. However, recirculation at the back of the occupant is not detected in the CFD simulation of the presented study. This might be due to the high turbulence intensity applied for the simulation and 
the less amount of information provided in the study. As a comparison between OHAD and UFAD airflow, OHAD airflow is relatively performed better in distributing the air evenly. Good air distribution generates a uniform temperature profile. The velocity of OHAD is less than the UFAD system by $0.4 \mathrm{~m} / \mathrm{s}$. However, the downward flow direction could not perform as good as upward flow in terms of removing the contaminant since the flow is going from ceiling to ceiling.

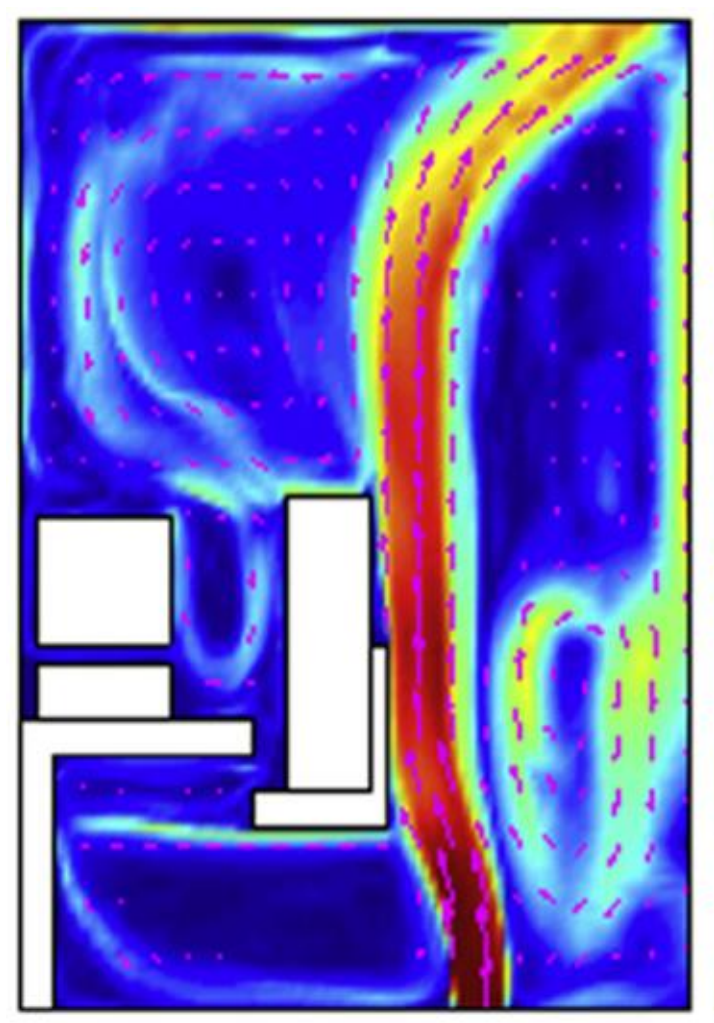

(a) From previous study Ho. et al., [13]

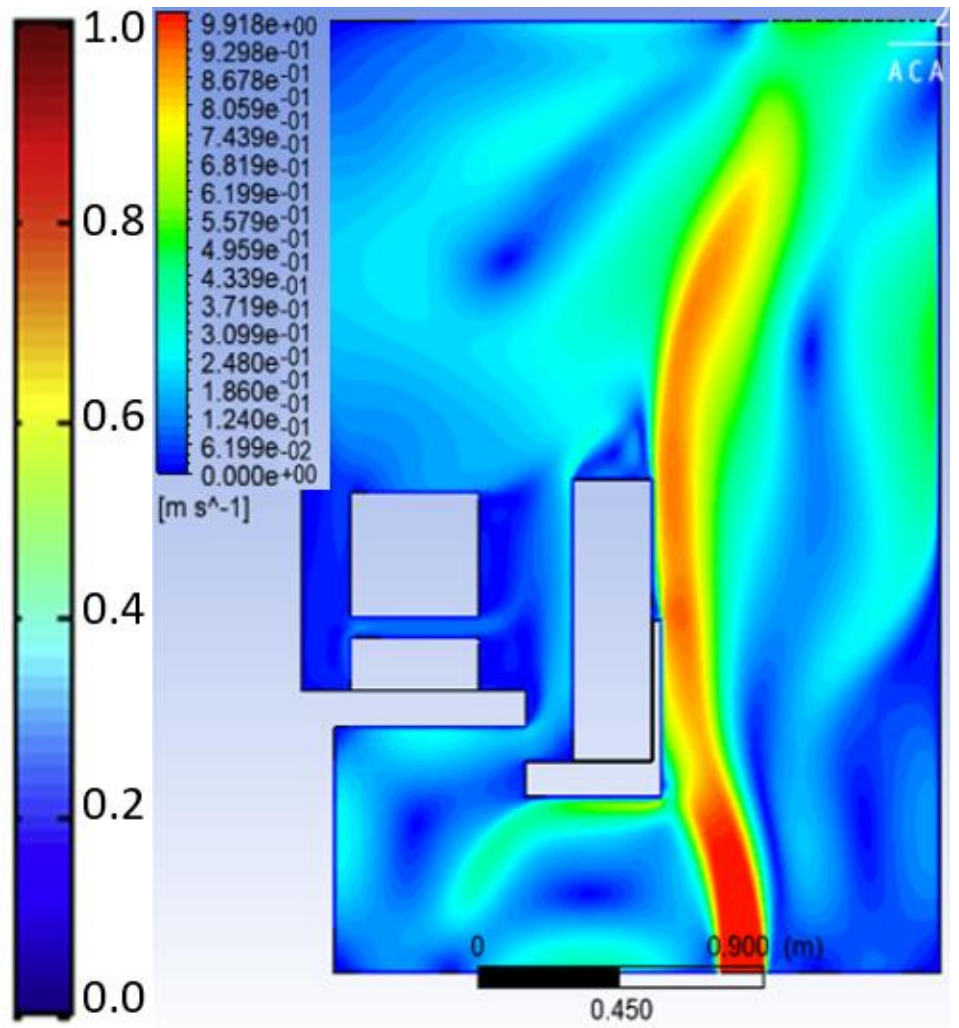

(b) For this study

Fig. 4. Velocity contours [m/sec] for UFAD system 


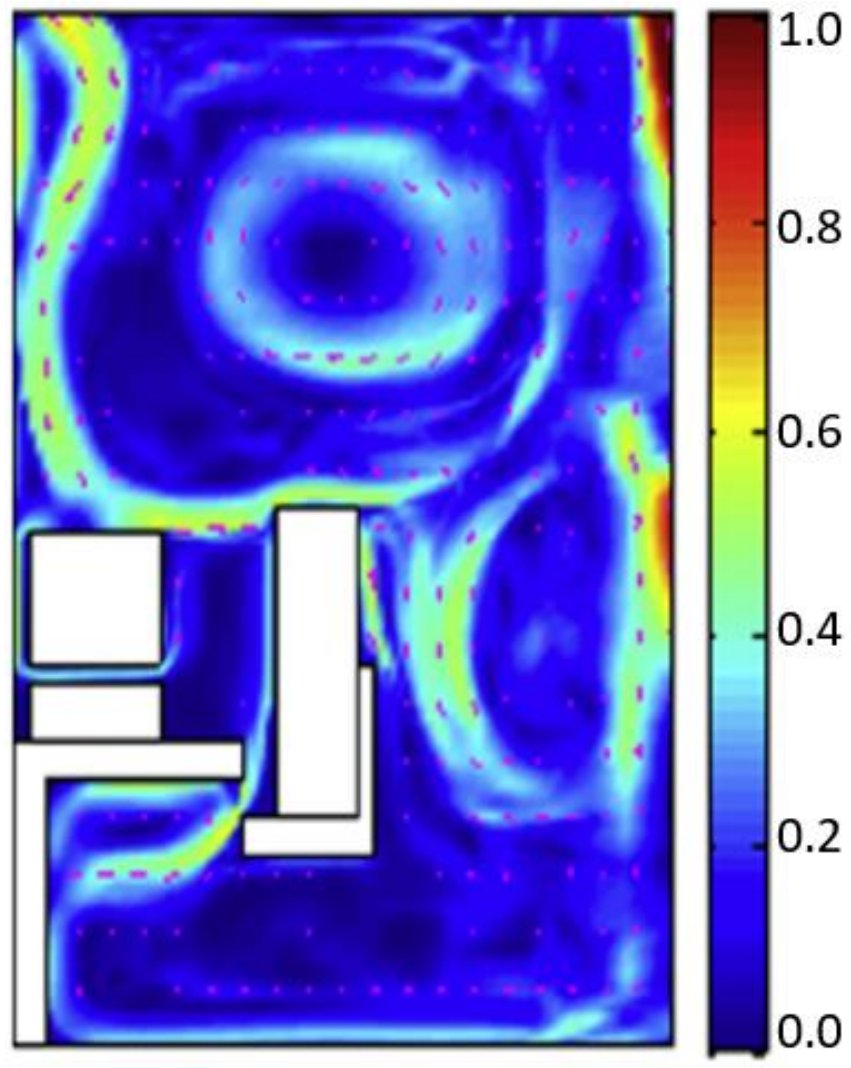

(a) From previous study Ho. et al., [13]

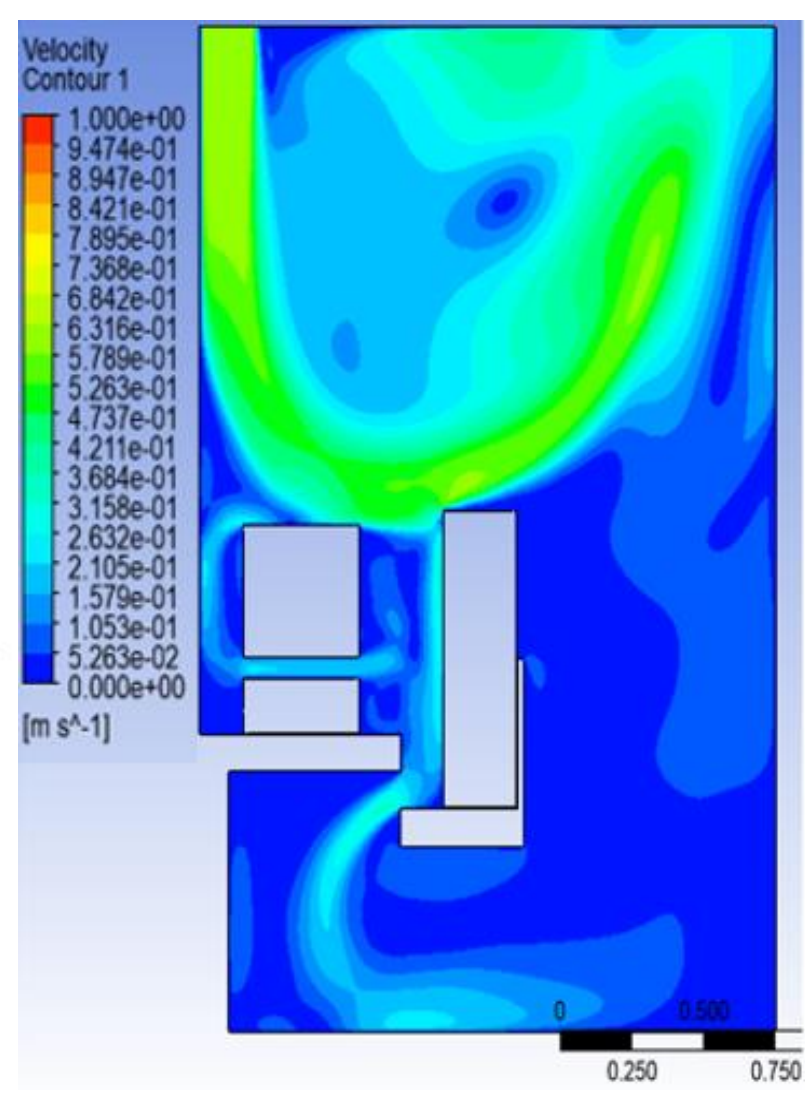

(b) For this study

Fig. 5. Velocity contours $[\mathrm{m} / \mathrm{sec}]$ for OHAD system

\subsection{Temperature Distribution}

Figure 6 compares the contours of the temperature distribution of reference $[13,19]$ and this study. It can be noticed that there are cooler regions spotted at the back of the occupant while warmer region at the front side. This could be attributed to the position of the diffuser which is located at the back side of the occupant. In addition, as a result of the non-well-mixed model criterion of UFAD system and hence producing a crystal-clear thermal zone in the room. The temperature used for UFAD system is slightly higher compare to OHAD system, which could potentially result in an energy saving as there is less power needed to pump the inside heat out of the room [8]. This statement also supported by Nada et al., [24]. ASHRAE standard $(2017)[7,19]$ suggested that temperature at the floor should be within the range of $19^{\circ} \mathrm{C}$ to $29^{\circ} \mathrm{C}$ to avoid 'cold feet' effect [13]. The temperature in the room increases as the height increases. The warmer region might be caused by the concentration of heat generation at that area and the lack of airflow through the region. However, the occupant can still experience thermal comfort because the temperature difference between ankle to head level does not go beyond $3^{\circ} \mathrm{C}$ as stated by [7]. According to Zheng et al., [25], UFAD system manage to maintain the average temperature of $26^{\circ} \mathrm{C}$ at the zone of human activity level or to be precise, the region below $2.0 \mathrm{~m}$ height. In order to observe the temperature profile in the room clearly and accurately, a graph of vertical temperature was plotted, as shown in Figure 7.

Figure 7 shows the vertical temperature of the office room with corresponding with the height of the room. From this graph, it can be observed that the temperature increases with the height. The point of interest of this graph is to identify whether the vertical temperature difference from the ankle level to the head level exceed $3^{\circ} \mathrm{C}$ or not. By referring to the height at $0.9 \mathrm{~m}$ to $1.8 \mathrm{~m}$, the temperature difference does not go beyond $3^{\circ} \mathrm{C}$. However, at $0.6 \mathrm{~m}$, the temperature is $26.85^{\circ} \mathrm{C}$. This 
is because the line applied in the CFD software to plot the graph located very close to the occupant. The temperature is high due to the body temperature of the occupant and heat flux generated by the occupant itself. Anyhow, the theory stated by Zheng et al., [25] has been proven in the attained of this simulation. The range of temperature also in the range of thermal comfort since it does not achieve $29^{\circ} \mathrm{C}$.

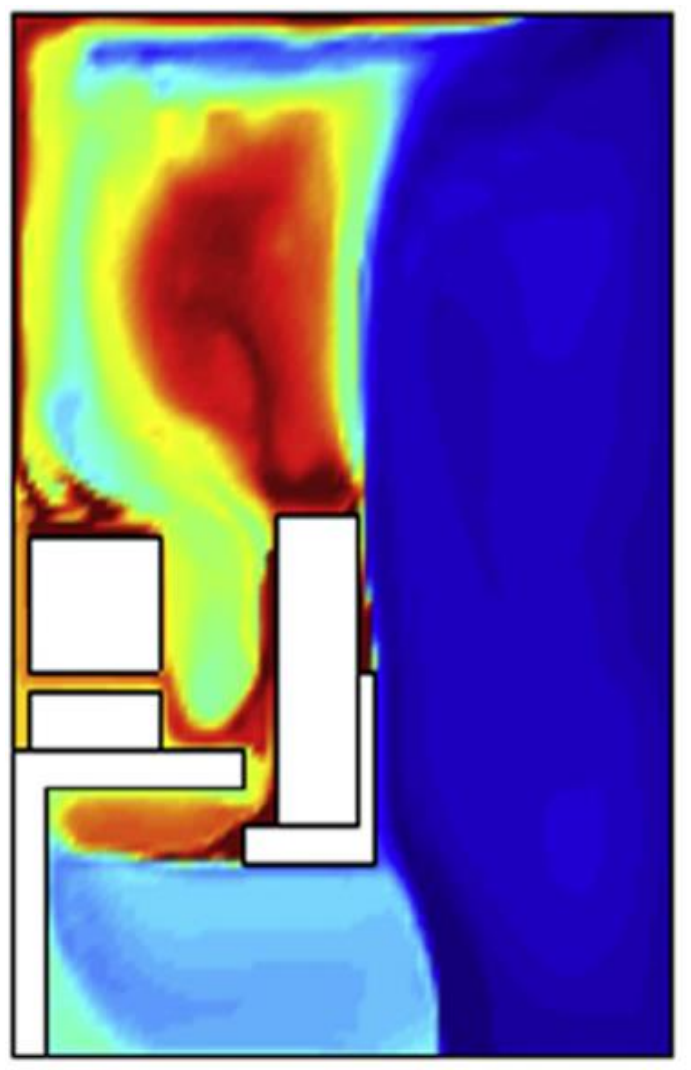

(a) From previous study Ho. et al., [13]

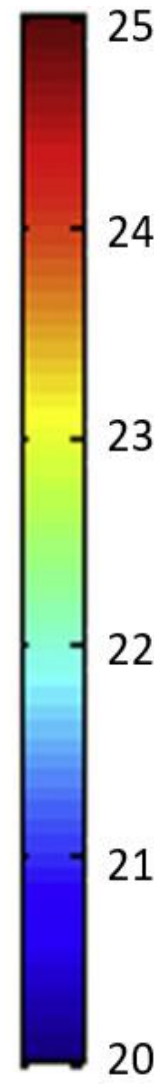

20

Fig. 6. Temperature contours [K] for UFAD system

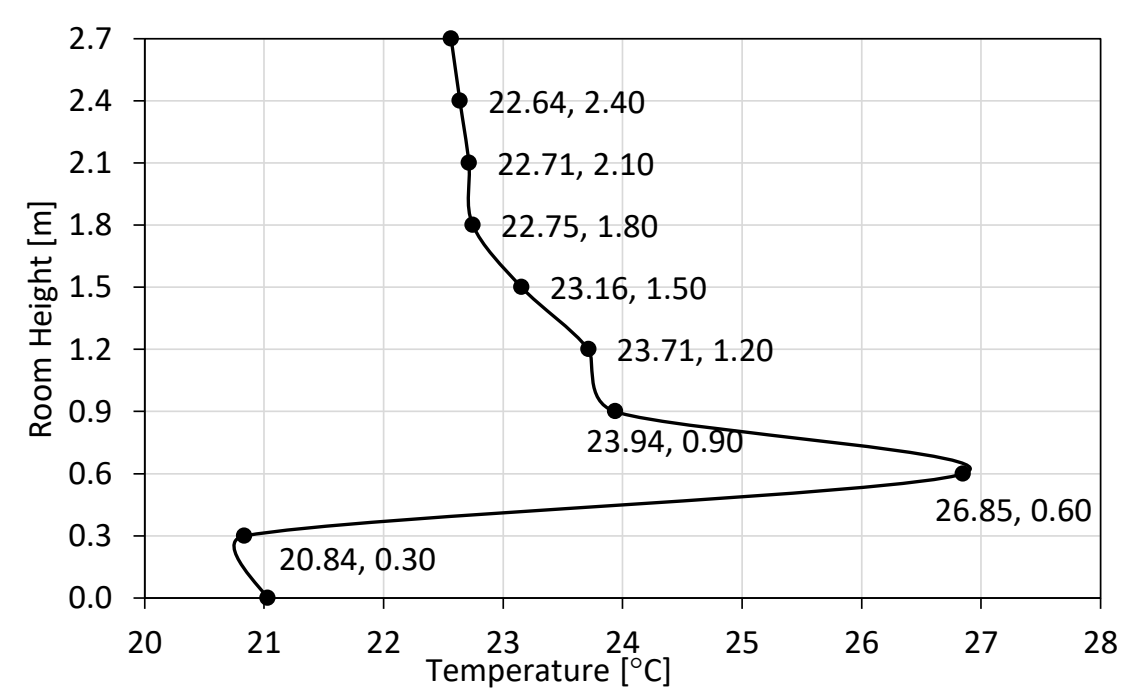

Fig. 7. Graph of height against vertical temperature for UFAD system

Figure 8 compares the temperature distribution contours of the OHAD model from reference [13] and from the CFD simulation of this study. As discussed earlier in air velocity distribution, the OHAD 
system produce more evenly temperature distribution compare to UFAD system due to its potential in providing better airflow distribution in a conditioned space. As a comparison between attained CFD results of reference [13] and this study, the air temperature of this study is found to be slightly colder. This difference could be caused by the unconfirmed values of heat generation parameters. However, similarities can still be seen between these two results. At the top and at the back of the occupant are found to be slightly warmer due to heat generated by lighting and occupant. The size of the warmer region above the occupant is larger than the one in the UFAD system but lower in temperature. In contrast, both UFAD and OHAD systems have potential in providing good IAQ based upon the temperature contours shown. Zheng et al., [25] who have done a simulation for UFAD and OHAD system found out that the temperature for OHAD system at a height of more than $1.2 \mathrm{~m}$ cannot be maintained at $26^{\circ} \mathrm{C}$ and below. The UFAD system however capable of maintaining the temperature of $26^{\circ} \mathrm{C}$ at a height below $2.0 \mathrm{~m}$. The authors supported the statement saying that UFAD system is better in providing thermal comfort to the occupants and better energy saving compare to OHAD system.

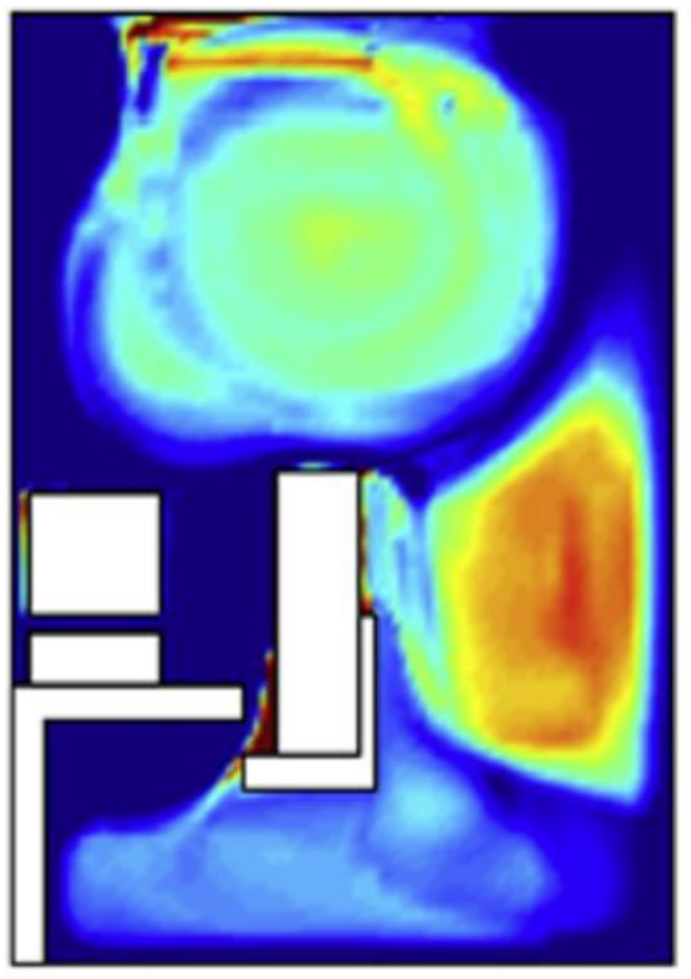

(a) From previous study Ho. et al., [13]

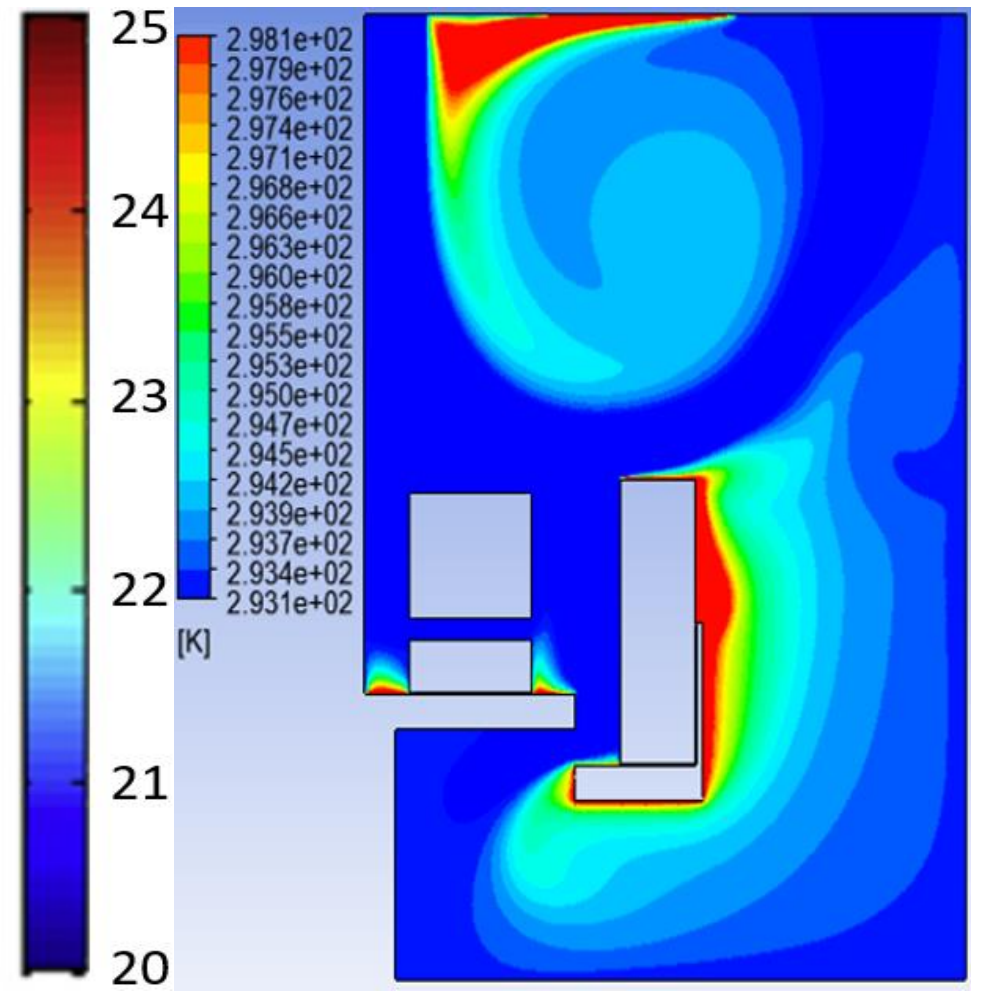

(b) For this study

Fig. 8. Temperature contours $[K]$ for OHAD system

Figure 9 shows the vertical temperature graph with respect to the height in the office room. It can be observed that the temperature at the ceiling is slightly colder than the temperature at the floor. Zheng et al., [25] stated that the temperature at the head of the occupant would be colder than the feet for the OHAD system and vice versa for the UFAD system. Fukao et al., [26] also stated the same theory. The line graph also clearly shows the sudden drop of temperature at $1.5 \mathrm{~m}$ and $1.8 \mathrm{~m}$ yet when comparing the value of the temperature, it is not significant. Besides, in order to evaluate the thermal comfort in term of vertical temperature, the temperature difference needs to be considered especially at the ankle to the head level. From the graph plotted, there is no vertical temperature difference achieve $3^{\circ} \mathrm{C}$. The range of temperature shown in the graph also much lower compare to the vertical temperature difference for UFAD system. This situation was mentioned by 
Fukao et al., [26] that UFAD system provide greater vertical temperature difference compare to OHAD system. Hence, the OHAD system could provide thermal comfort to the occupant in term of the air temperature distribution.

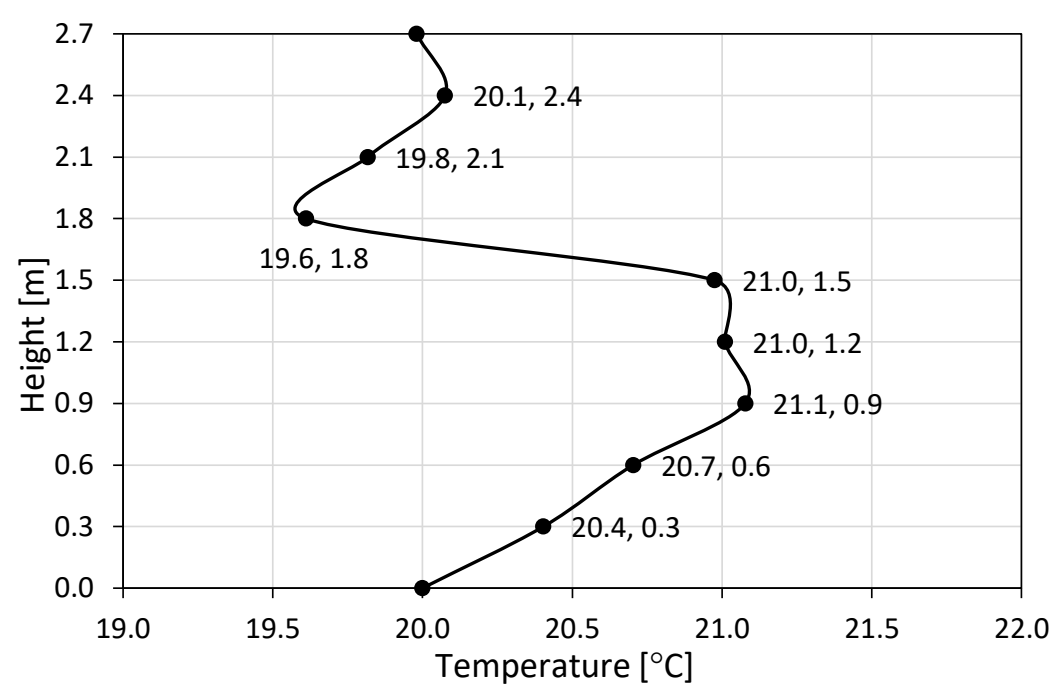

Fig. 9. Graph of height against vertical temperature for OHAD system

\subsection{Relative Humidity}

Figure 10 shows the simulation results of relative humidity contours for UFAD system from reference [13] and the presented study. It can be noticed that the UFAD system produces a clear separation between high relative humidity and low relative humidity due to the poor air distribution. It is expected to observe that the back region of the occupant is dominated with high relative humidity percentage because of the position of the inlet diffuser. The diffuser is the source of the air humidity. The frontal area has a relative humidity of $50 \%$ to $60 \%$ while the back area has a relative humidity of $75 \%$ to $80 \%$. Fukao et al., [26] who conducted the same design of UFAD system stated that the reason of low level of humidity detected at the occupant's region could be attributed to the high air temperature at that region. The mass ratio is not given from the article, yet the value used for this simulation is still in the range of less than $0.012(\mathrm{~kg} . \mathrm{H} 2 \mathrm{O} / \mathrm{kg})$ dry air as recommended by ASHRAE Standard [7]. Overall, if the UFAD system is utilized in a building, the occupant might face a dryer environment if the diffuser is located at the back of the occupant.

Figure 11 displays the CFD simulation results of the relative humidity contour for the OHAD system from reference [13] and the presented study. The pattern of relative humidity percentage for both results is slightly differed to each other. By referring to the humidity contour of this study, huge part of the main flow is making a curve towards the outlet vent while reference [13] results showing that the flow of relative humidity goes down passing through the obstacle from the computer and occupant. This variance could be due to the unclear mass ratio and turbulence intensity. However, the turbulence intensity applied obeys the range declared by ASHRAE Standard [7], which is less than $3 \%$. It can be observed that from the comparison with the UFAD system, the OHAD system provide better humidity level. 


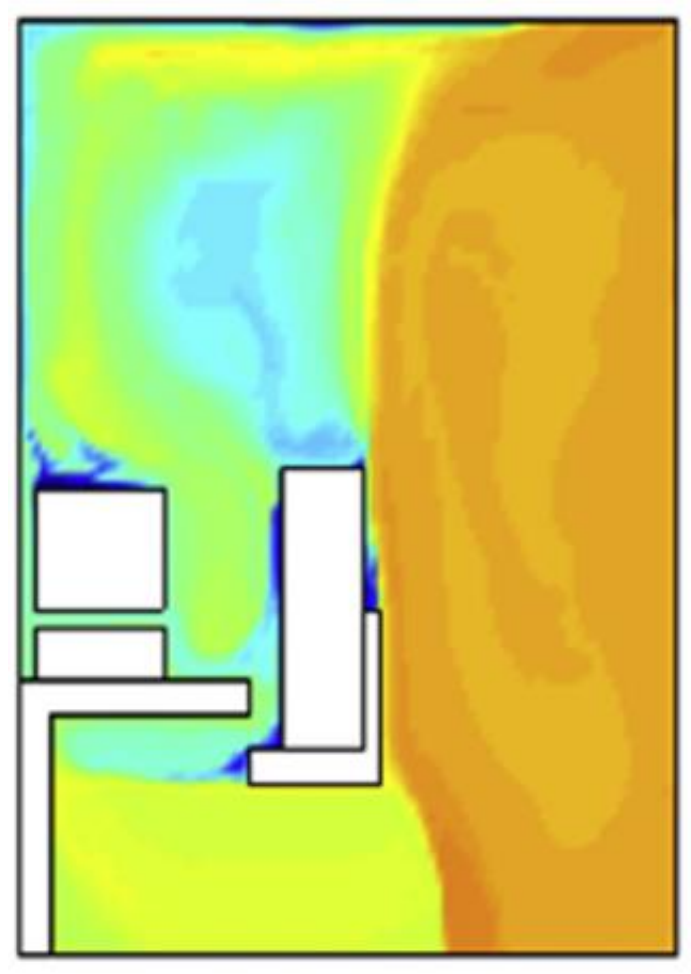

(a) From previous study Ho. et al., [13]

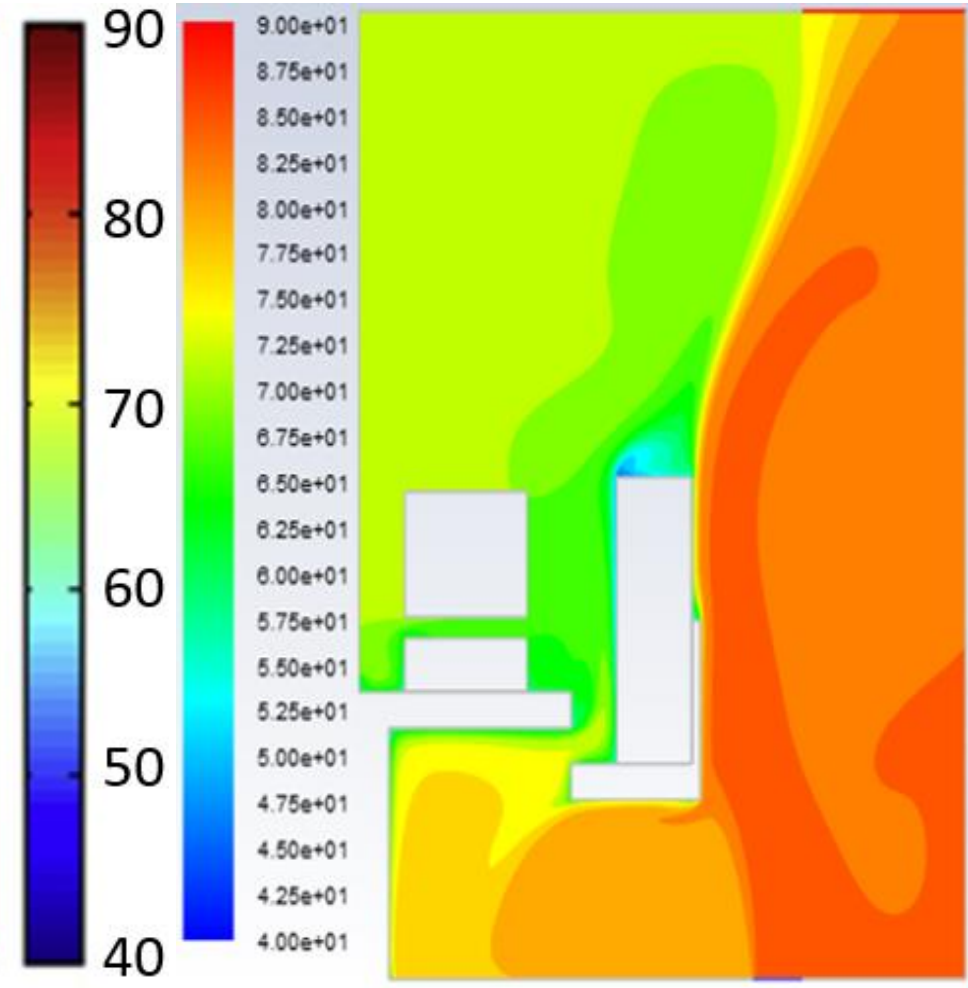

(b) For this study

Fig. 10. Relative humidity contours for UFAD system

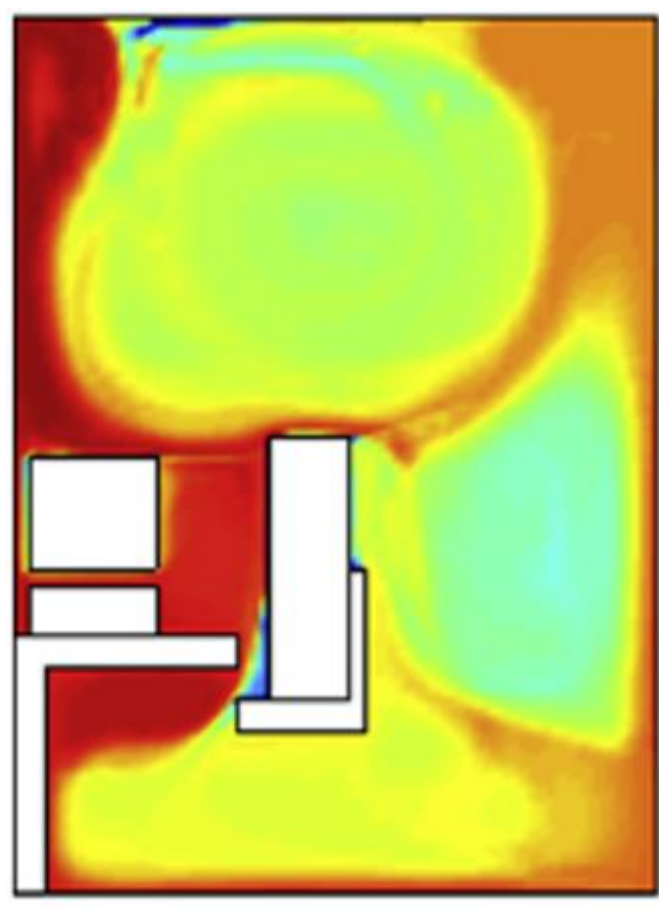

(a) From previous study Ho. et al., [13]

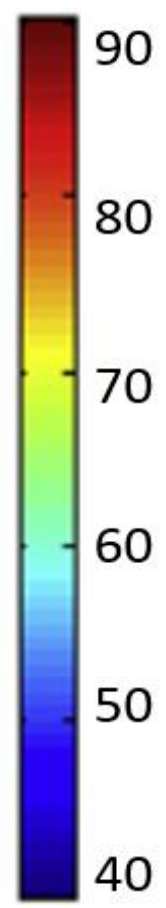

Fig. 11. Relative humidity contours for OHAD system

\subsection{Temperature Distribution with Two Occupants}

Figure 12 shows the temperature distribution contours for the UFAD and OHAD systems with two occupants. For UFAD system, the temperature distribution is more uniform. There is a huge region 
of cold found at the top and back side of the occupants while warmer region only spotted at the under-desk area. For OHAD system, the temperature in the room is not distributed evenly compare to UFAD system. Even though the minimum temperature detected at the head level of the occupant, the heat is concentrated at the middle of the room due to the low temperature distribution. Therefore, occupants with UFAD utilized system could feel thermally comfort compare to OHAD utilized system.

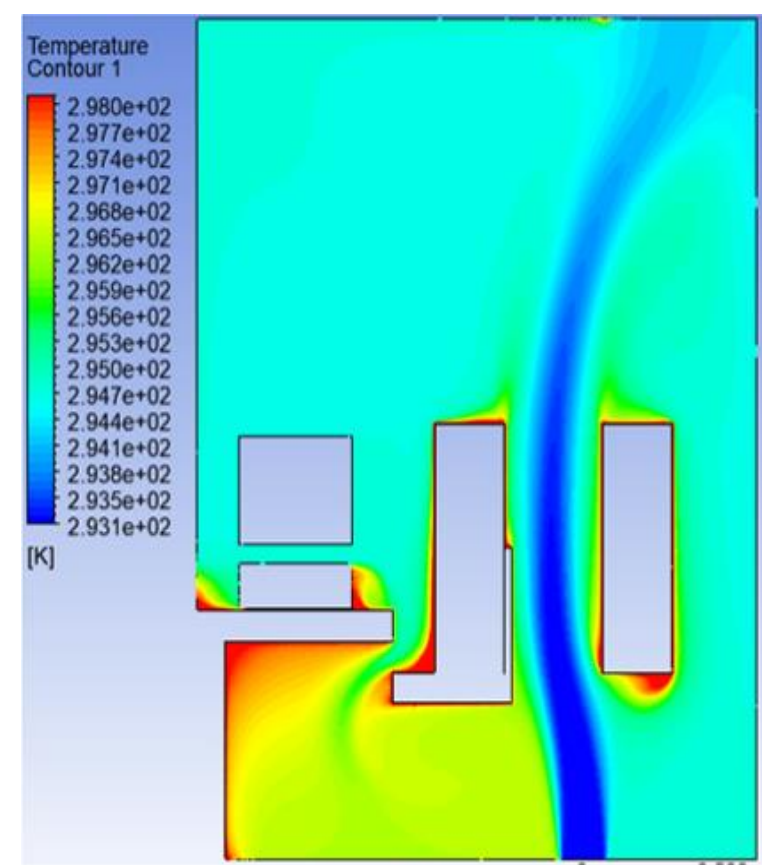

(a) For UFAD system

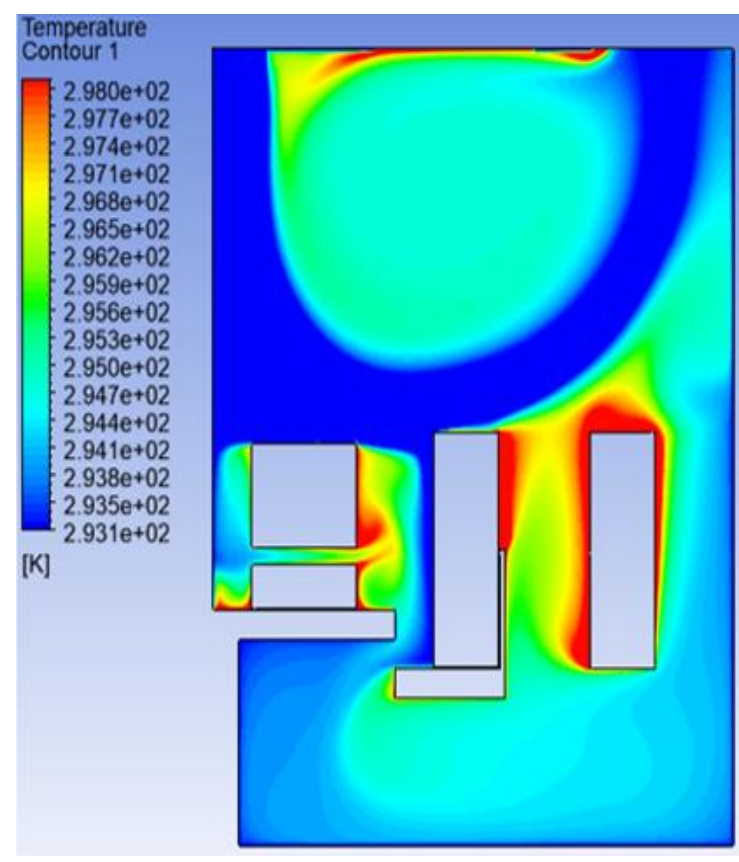

(b) For UFAD system

Fig. 12. Temperature contour for (a) UFAD (b) OHAD system with two occupants

\subsection{Air Velocity Distribution for Two Occupants}

Figure 13 shows the velocity contour for UFAD and OHAD systems with two occupants. As for the OHAD system, the airflow pattern is similar to the previous simulation. Only a small part of the main flow goes through the gap between occupant and computer. The second occupant may not experience the windy effect from the inlet airflow. For the UFAD system, it can be noticed that the airflow passes through the gap between two occupants. Some of the flow fills up the gap between the occupant and the desk. Since the velocity for UFAD system is relatively higher than the OHAD system, the second occupant might experience 'cold feet'. The second occupant may feel thermal discomfort due to excessively cold temperature at his or her feet. 


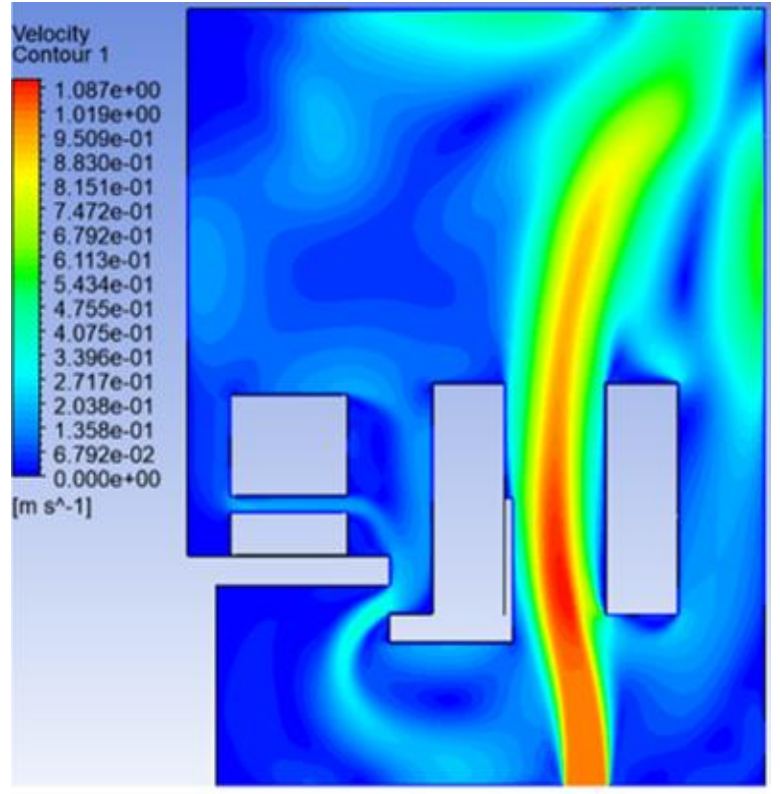

(a) For UFAD system

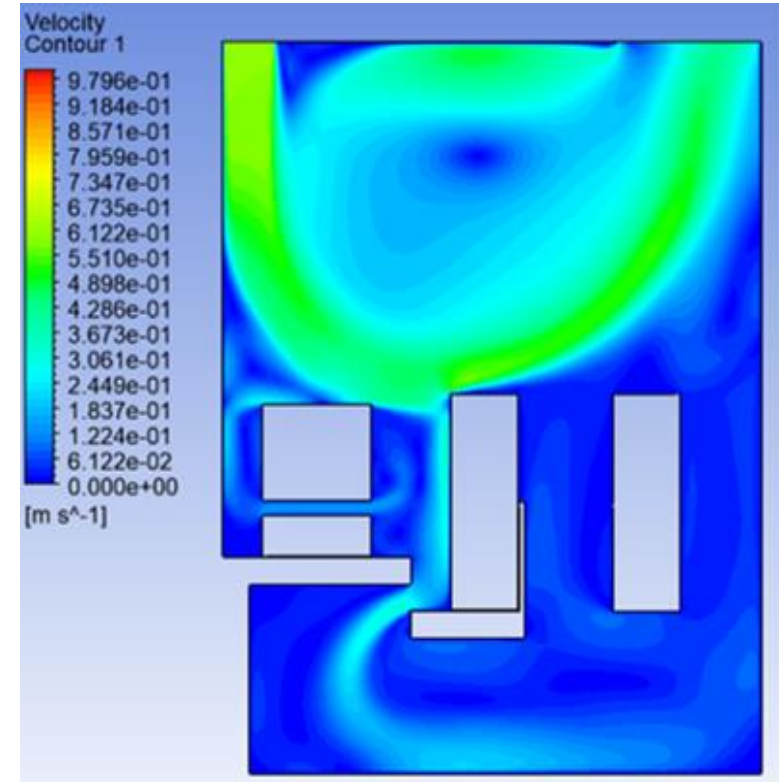

(b) For UFAD system

Fig. 13. Velocity contour for (a) UFAD (b) OHAD system with two occupants

\subsection{Air Velocity Distribution when the Diffuser is Under the Desk}

Figure 14-a shows the velocity contour for UFAD system when the diffuser locates underneath the desk. It can be seen from the velocity distribution contour; the main flow is divided into two subflows once it collides with the chair. The first sub-flow goes horizontally straight and directly straight upward as it hits the wall. The second sub-flow goes in between the occupant and the desk. The airflow is not distributed evenly. The high velocity at the leg area of the occupant potentially could cause a thermal discomfort. In real life cases, the flow of the air from the diffuser is not supposed to be like this. The temperature profile is highly dependent on the supplied airflow when the temperature is measured near the supply diffuser. Tsai et al., [11] also supported this statement.

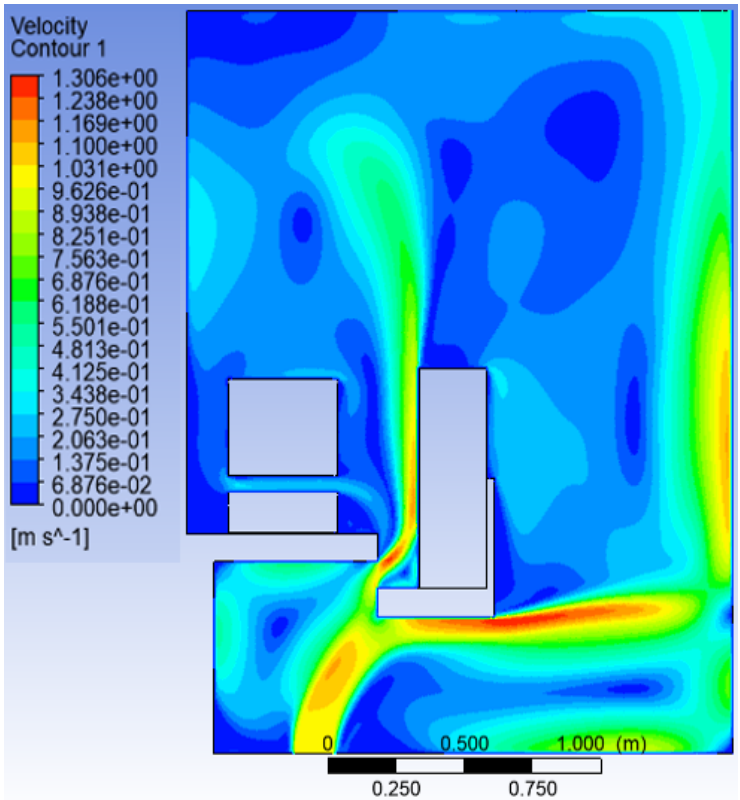

(a) Velocity contour

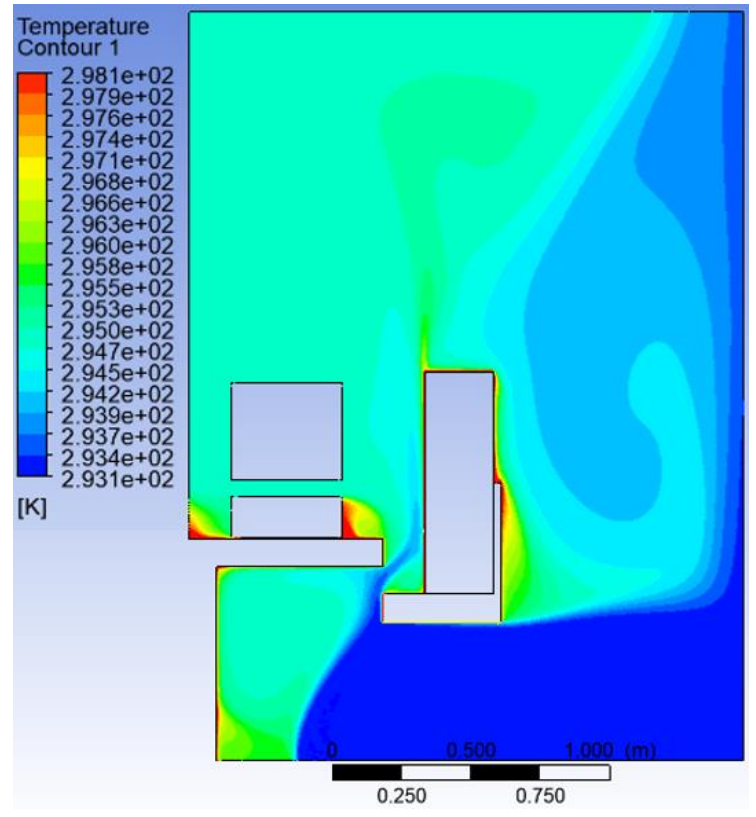

(b) Temperature contour

Fig. 14. Temperature and velocity contours for UFAD system with diffuser located under the desk 


\subsection{Temperature Distribution when the Diffuser is Under the Desk}

Figure 14-b shows the temperature distribution contour for the UFAD system when the diffuser located underneath the desk. Only small area in the room is filled with cold air while the rest is slightly warmer. Lack of air distribution caused the bottom area to be colder than the top. The inlet air cannot be distributed evenly because of the obstacles that block the pathway of the inlet air. Due to the obstacles, the inlet air tends to move horizontally to avoid them. Even though the position of the diffuser is expected to be ideal to effectively generate thermal comfort to the occupant, it is not enough due to the straight airflow characteristic. From Figure 14-b, it can be concluded that the it is not ideal to install a direct diffuser underneath the desk of the occupant. However, the thermal performance can be different if a swirl diffuser is applied. According to Kim et al., [27], increasing the value of inlet angle of swirl diffuser could adversely influence the occupant's thermal comfort. If smaller value of inlet angle of diffuser is applied, the air supply tends to lose its momentum and hence spread the air horizontally. Hence, if it is decided to install a diffuser underneath the desk, it is necessary to install a higher angle of swirl diffuser to maintain the throw height of the supplied air.

Figure 15 shows the air temperature gradient against the height of the proposed room for the model with different location of the adopted diffusers. This graph is plotted to determine whether the vertical temperature difference exceed $3^{\circ} \mathrm{C}$ or not. It can be noticed that at $0.60 \mathrm{~m}$ the temperature is the highest which is $26.85^{\circ} \mathrm{C}$. This is because the position of line to measure the vertical temperature is too close to the occupant and desk. By referring to the pattern of temperature from $0.90 \mathrm{~m}$ and above, the temperature profile is considered to be uniform at $21^{\circ} \mathrm{C}$. Since the measuring line is located in front of the occupant, it can be concluded that the occupant could probably feel thermally comfort.

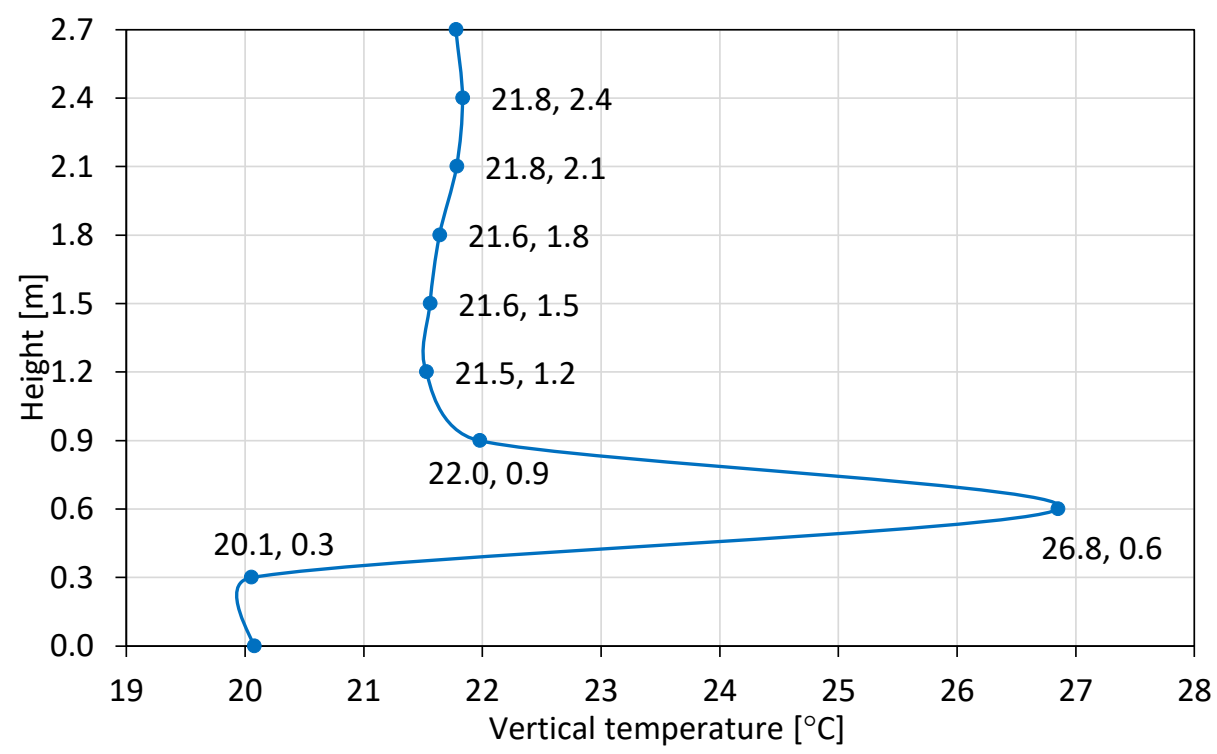

Fig. 15. Graph for height against vertical temperature for different location of diffuser

\section{Conclusions}

In this study, a CFD analysis was conducted aiming to investigate the thermal performance of the UFAD system to partly cool down an occupied room with one and two occupants. The attained CFD results were compared with that of the OHAD system performance in terms of the air-flow velocity and temperature distributions, energy consumption and occupants comfort level. Comparisons were 
conducted between the achieved simulations' results in this study with the previously published simulation results in reference [13]. The comparison comprised many fundamental parameters such as the airflow velocity and the temperature distribution inside the occupied room. Due to the complexity of the thermal comfort measures, ASHRAE Standard $[7,21]$ became the main reference in determining the thermal comfort level.

It can be concluded that the UFAD system could have superior thermal performance compared to that of the OHAD system although the OHAD system still has some advantages. In specific, the UFAD system could provide the best thermal performance whereas the OHAD system was found to be less efficient in providing thermal comfort to the occupant and consumed a higher amount of energy. This is because it is required to cool down the whole room instead of being cooled partly. The computational results affirmed that the UFAD system was able to maintain the room temperature at around $26^{\circ} \mathrm{C}$ at a height below $2.0 \mathrm{~m}$ compared to $1.2 \mathrm{~m}$ of the OHAD system. In conclusion, the UFAD system could provide better indoor air quality, and it could have superior thermal performance for the tropic weather regions such as Malaysia compared to that of the OHAD system.

\section{Acknowledgement}

The authors would like to acknowledge the publication support through Bold Fund provided by Universiti Tenaga Nasional (UNITEN), Project No. J510050002/2021060.

\section{References}

[1] Dheyab, Hussam S., Manar Salih Mahdi Al-Jethelah, Tadahmun Ahmed Yassen, and Thamir Khalil Ibrahim. "Experimental study of the optimum air gap of a rectangular solar air heater." Journal of Advanced Research in Fluid Mechanics and Thermal Sciences 59, no. 2 (2019): 318-329.

[2] Guan, Lisa. "Energy use, indoor temperature and possible adaptation strategies for air-conditioned office buildings in face of global warming." Building and Environment 55 (2012): 8-19. https://doi.org/10.1016/i.buildenv.2011.11.013

[3] Azmi, Mohd Irwan Mohd, Nor Azwadi Che Sidik, Yutaka Asako, Wan Mohd Arif Aziz Japar, Nura Muaz Muhammad, and Nadlene Razali. "Numerical Studies on PCM Phase Change Performance in Bricks for Energy-Efficient Building Application-A Review." Journal of Advanced Research in Numerical Heat Transfer 1, no. 1 (2020): 13-21.

[4] Westphalen, Detlef, and Scott Koszalinski. "Energy consumption characteristics of commercial building hvac systems volume I: Chillers, refrigerant compressors, and heating systems." Final Report to the Department of Energy (Contract No. DE-AC01-96CE23798) (2001).

[5] Muhieldeen, Mohammed W., Lim Chong Lye, M. S. S. Kassim, Tey Wah Yen, and K. H. Teng. "Effect of Rockwool Insulation on Room Temperature Distribution." Journal of Advanced Research in Experimental Fluid Mechanics and Heat Transfer 3, no. 1 (2021): 9-15.

[6] Wijaya, Elang Pramudya, and Ardiyansyah Saad Yatim. "Numerical Investigation of Air Movement on Laboratory Scale Psychrometric Chamber." Journal of Advanced Research in Fluid Mechanics and Thermal Sciences 84, no. 2 (2021): 82-91. https://doi.org/10.37934/arfmts.84.2.8291

[7] American Society of Heating and Air-Conditioning Engineers (ASHAE), STANDARD 55 - THERMAL ENVIRONMENTAL CONDITIONS FOR HUMAN OCCUPANCY. 2017.

[8] Nicol, J. Fergus, and Michael A. Humphreys. "Adaptive thermal comfort and sustainable thermal standards for buildings." Energy and buildings 34, no. 6 (2002): 563-572. https://doi.org/10.1016/S0378-7788(02)00006-3

[9] Khan, Muhammad Hammad, and William Pao. "Thermal comfort analysis of PMV model prediction in air conditioned and naturally ventilated buildings." Energy Procedia 75 (2015): 1373-1379. https://doi.org/10.1016/i.egypro.2015.07.218

[10] Alajmi, Ali, and Wid El-Amer. "Saving energy by using underfloor-air-distribution (UFAD) system in commercial buildings." Energy conversion and management 51, no. 8 (2010): $1637-1642$. https://doi.org/10.1016/j.enconman.2009.12.040

[11] Tsai, Ting-Ya, Ren-Hao Liou, and Yi-Jiun Peter Lin. "An experimental study on the indoor environment using UnderFloor Air Distribution system." Procedia Engineering $79 \quad$ (2014): $263-266$. https://doi.org/10.1016/j.proeng.2014.06.341 
[12] Jerry Sipes. Tech Tips / Overhead Air Distribution Systems, . 2010.

[13] Ho, Son H., Luis Rosario, and Muhammad M. Rahman. "Comparison of underfloor and overhead air distribution systems in an office environment." Building and Environment 46, no. 7 (2011): 1415-1427. https://doi.org/10.1016/i.buildenv.2011.01.008

[14] McQuiston, Faye C., Jerald D. Parker, and Jeffrey D. Spitler. Heating, ventilating, and air conditioning: analysis and design. John Wiley \& Sons, 2004.

[15] Fekadu, Birlie, and H. V. Harish. "Numerical Studies on Thermo-Hydraulic Characteristics of Turbulent Flow in a Tube with a Regularly Spaced Dimple on Twisted Tape." CFD Letters 13, no. 8 (2021): 20-31. https://doi.org/10.37934/cfdl.13.8.2031

[16] Abed, Azher M., Doaa Fadhil Kareem, Hasan Sh Majdi, and Ammar Abdulkadhim. "Experimental and CFD Analysis of Two-Phase Forced Convection Flow in Channels of Various Rib Shapes." Journal of Advanced Research in Fluid Mechanics and Thermal Sciences 77, no. 1 (2021): 36-50. https://doi.org/10.37934/arfmts.77.1.3650

[17] Alfarawi, Suliman SS, Azeldin El-sawi, and Hossin Omar. "Exploring Discontinuous Meshing for CFD Modelling of Counter Flow Heat Exchanger." Journal of Advanced Research in Numerical Heat Transfer 5, no. 1 (2021): 26-34.

[18] Fathinia, F., and Ahmed Kadhim Hussein. "Effect of blockage shape on unsteady mixed convective nanofluid flow over backward facing step." CFD Letters 10, no. 1 (2018): 1-18.

[19] Ibrahim, Thamir K., Ahmed T. Al-Sammarraie, Manar SM Al-Jethelah, Wadhah H. Al-Doori, Mohammad Reza Salimpour, and Hai Tao. "The impact of square shape perforations on the enhanced heat transfer from fins: Experimental and numerical study." International Journal of Thermal Sciences 149 (2020): 106144. https://doi.org/10.1016/i.ijthermalsci.2019.106144

[20] Ibrahim, Thamir K., Ahmed T. Al-Sammarraie, Wadhah H. Al-Taha, Mohammad Reza Salimpour, Manar Al-Jethelah, Ahmed N. Abdalla, and Hai Tao. "Experimental and numerical investigation of heat transfer augmentation in heat sinks using perforation technique." Applied Thermal Engineering $160 \quad$ (2019): 113974. https://doi.org/10.1016/i.applthermaleng.2019.113974

[21] ASHRAE Standing Standard Project Committee 55, Thermal Environmental Conditions for Human Occupancy. 2017.

[22] A/L Sambathan, Sures, Firas Basim Ismail, and M. S. Nasif. "Underfloor air distribution technology: A review." In AIP Conference Proceedings, vol. 2035, no. 1, p. 070004. AIP Publishing LLC, 2018. https://doi.org/10.1063/1.5075594

[23] Wiriyasart, Songkran, and Paisarn Naphon. "Numerical study on air ventilation in the workshop room with multiple heat sources." Case Studies in Thermal Engineering $13 \quad$ (2019): 100405. https://doi.org/10.1016/i.csite.2019.100405

[24] Nada, S. A., H. M. El-Batsh, H. F. Elattar, and N. M. Ali. "CFD investigation of airflow pattern, temperature distribution and thermal comfort of UFAD system for theater buildings applications." Journal of Building Engineering 6 (2016): 274-300. https://doi.org/10.1016/i.jobe.2016.04.008

[25] Zheng, Chenxiao, Hongbo Liang, Shijun You, Wandong Zheng, and Zeqin Liu. "Numerical Simulation and Experimental Study of Comfort Air Conditioning Influenced by Bottom-supply and Stratum Ventilation Modes." Energy Procedia 105 (2017): 3609-3615. https://doi.org/10.1016/i.egypro.2017.03.833

[26] Fukao, H., M. Oguro, M. Ichihara, and Sh Tanabe. "Comparison of underfloor vs. overhead air distribution systems in an office building." ASHRAE Transactions 108, no. 1 (2002): 64-76.

[27] Kim, Gon, Laura Schaefer, Tae Sub Lim, and Jeong Tai Kim. "Thermal comfort prediction of an underfloor air distribution system in a large indoor environment." Energy and Buildings 64 (2013): $323-331$. https://doi.org/10.1016/i.enbuild.2013.05.003 